\title{
Some fixed and coincidence point theorems for expansive maps in cone metric spaces
}

\author{
Wasfi Shatanawi and Fadi Awawdeh*
}

* Correspondence: awawdeh@hu. edu.jo

Department of Mathematics, Hashemite University, Zarqa 13115, Jordan

\begin{abstract}
In this article, we establish some common fixed and common coincidence point theorems for expansive type mappings in the setting of cone metric spaces. Our results extend some known results in metric spaces to cone metric spaces. Also, we introduce some examples the support the validity of our results.

Mathematics Subject Classification: 54H25; 47H10; 54E50.
\end{abstract}

Keywords: common fixed point, cone metric space, coincidence fixed point

\section{Introduction}

Huang and Zhang [1] introduced the notion of cone metric spaces as a generalization of metric spaces. They replacing the set of real numbers by an ordered Banach space. Huang and Zhang [1] presented the notion of convergence of sequences in cone metric spaces and proved some fixed point theorems. Then after, many authors established many fixed point theorems in cone metric spaces. For some fixed point theorems in cone metric spaces we refer the reader to [2-30].

In the present article, $E$ stands for a real Banach space.

Definition 1.1. Let $P$ be a subset of $E$ with $\operatorname{Int}(P) \neq \varnothing$. Then $P$ is called a cone if the following conditions are satisfied:

(1) $P$ is closed and $P \neq\{\theta\}$.

(2) $a, b \in \mathbf{R}^{+}, x, y \in P$ implies $a x+b y \in P$.

(3) $x \in P \cap-P$ implies $x=\theta$.

For a cone $P$, define a partial ordering $\leqslant$ with respect to $P$ by $x \leqslant y$ if and only if $y$ $x \in P$. We shall write $x \prec y$ to indicate that $x \leqslant y$ but $x \neq y$, while $x \ll y$ will stand for $y-x \in \operatorname{Int} P$. It can be easily shown that $\lambda \operatorname{Int}(P) \subseteq \operatorname{Int}(P)$ for all positive scalar $\lambda$.

Definition 1.2. [1] Let $X$ be a nonempty set. Suppose the mapping $d: X \times X \rightarrow E$ satisfies

(1) $\theta \prec d(x, y)$ for all $x, y \in X$ and $d(x, y)=\theta$ if and only if $x=y$.

(2) $d(x, y)=d(y, x)$ for all $x, y \in X$.

(3) $d(x, y) \leqslant d(x, z)+d(y, z)$ for all $x, y \in X$.

Then $d$ is called a cone metric on $X$, and $(X, d)$ is called a cone metric space.

\section{Springer}

(C) 2012 Shatanawi and Awawdeh; licensee Springer. This is an Open Access article distributed under the terms of the Creative Commons Attribution License (http://creativecommons.org/licenses/by/2.0), which permits unrestricted use, distribution, and reproduction in any medium, provided the original work is properly cited. 
Definition 1.3. [1] Let $(X, d)$ be a cone metric space. Let $\left(x_{n}\right)$ be a sequence in $X$ and $x \in X$. If for every $c \in E$ with $\theta \ll c$, there is an $N \in \mathbf{N}$ such that $d\left(x_{n}, x\right) \ll c$ for all $n$ $\geq N$, then $\left(x_{n}\right)$ is said to be convergent and $\left(x_{n}\right)$ converges to $x$ and $x$ is the limit of $\left(x_{n}\right)$. We denote this by $\lim _{n \rightarrow+\infty} x_{n}=x$ or $x_{n} \rightarrow x$ as $n \rightarrow+\infty$. If for every $c \in E$ with $\theta \ll c$ there is an $N \in \mathbf{N}$ such that $d\left(x_{n}, x_{m}\right) \ll c$ for all $n, m \geq N$, then $\left(x_{n}\right)$ is called a Cauchy sequence in $X$. The space $(X, d)$ is called a complete cone metric space if every Cauchy sequence is convergent.

The cone $P$ in a real Banach space $E$ is called normal if there is a number $\lambda>0$ such that for all $x, y \in E$,

$$
\theta \preccurlyeq x \preccurlyeq y \text { implies }\|x\| \leq \lambda\|y\| \text {. }
$$

Iiker \ahin and Mustafa Telci [30] studied a theorem on common fixed points of expansive type mappings in cone metric spaces.

Definition 1.4. [30] Let $E$ and $F$ be real Banach spaces and $P$ and $Q$ be cones in $E$ and $F$, respectively. Let $(X, d)$ and $(Y, \rho)$ be cone metric spaces, where $d: X \times X \rightarrow E$ and $\rho: Y \times Y \rightarrow F$. A function $f: X \rightarrow Y$ is said to be continuous at $x_{0} \in X$, if for every $c L F$ with $0 \ll c$, there exists $b \in E$ with $0 \ll b$ such that $\rho\left(f x, f x_{0}\right) \ll c$ whenever $x \in$ $X$ and $d\left(x, x_{0}\right) \ll b$.

Lemma 1.1. [30] Let $(X, d)$ and $(Y, \rho)$ be cone metric spaces. A function $f: X \rightarrow Y$ is continuous at a point $x_{0} \in X$ if and only if whenever a sequence $\left(x_{n}\right)$ in $X$ converges to $x_{0}$, the sequence $\left(f x_{n}\right)$ converges to $f x_{0}$.

Theorem 1.1. [30] Let $(X, d)$ be a complete cone metric space and $P$ be a cone. Let $f$ and $g$ be surjective self-mappings of $X$ satisfying the following inequalities

$$
\begin{aligned}
& d(g f x, f x) \succcurlyeq a d(f x, x), \\
& d(f g x, g x) \succcurlyeq b d(g x, x)
\end{aligned}
$$

for all $x \in X$, where $a, b>1$. If either $f$ or $g$ is continuous, then $f$ and $g$ have a common fixed point.

The aim of this article is to study new theorems of common fixed and coincidence point for expansive mappings in cone metric spaces under a set of conditions. Our results generalize several well known comparable results in the literature. Also, we introduced some examples to support the validity of our results.

\section{Main results}

We start with the following theorem

Theorem 2.1. Let $(X, d)$ be a cone metric space with a solid cone P. Let $T, f: X \rightarrow X$ be mappings satisfying:

$$
d(T x, T y) \succcurlyeq a d(f x, f y)+b d(f x, T x)+c d(f y, T y)
$$

for all $x, y \in X$ where $a, b, c \geq 0$ with $a+b+c>1$. Suppose the following hypotheses:

(1) $b<1$ or $c<1$.

(2) $f X \subseteq T X$.

(3) TX is a complete subspace of $X$.

Then $T$ and $f$ have a coincidence point. 
Proof. Let $x_{0} \in X$. Since $f X \subseteq T X$, we choose $x_{1} \in X$ such that $T x_{1}=f x_{0}$. Again, we can choose $x_{2} \in X$ such that $T x_{2}=f x_{1}$. Continuing in the same way, we construct a sequence $\left(x_{n}\right)$ in $X$ such that $T x_{n+1}=f x_{n}$ for all $n \in \mathbf{N} \cup\{\mathbf{0}\}$.

If $f x_{m-1}=f x_{m}$ for some $m \in \mathbf{N}$, then $T x_{m}=f x_{m}$. Thus $x_{m}$ is a coincidence point of $T$ and $f$.

Now, assume that $x_{n-1} \neq x_{n}$ for all $n \in \mathbf{N}$.

Case (1): Suppose $b<1$.

By (1), we have

$$
\begin{aligned}
d\left(f x_{n-1}, f x_{n}\right) & =d\left(T x_{n}, T x_{n+1}\right) \\
& \succcurlyeq a d\left(f x_{n}, f x_{n+1}\right)+b d\left(f x_{n}, T x_{n}\right)+c d\left(f x_{n+1}, T x_{n+1}\right) \\
& =a d\left(f x_{n}, f x_{n+1}\right)+b d\left(f x_{n}, f x_{n-1}\right)+c d\left(f x_{n+1}, f x_{n}\right) .
\end{aligned}
$$

Thus, we have

$$
(1-b) d\left(f x_{n-1}, f x_{n}\right) \succcurlyeq(a+c) d\left(f x_{n+1}, f x_{n}\right) .
$$

Hence

$$
d\left(f x_{n+1}, f x_{n}\right) \preccurlyeq \frac{1-b}{a+c} d\left(f x_{n-1}, f x_{n}\right) .
$$

Case (2): Suppose $c<1$.

By (1), we have

$$
\begin{aligned}
d\left(f x_{n}, f x_{n-1}\right) & =d\left(T x_{n+1}, T x_{n}\right) \\
& \succcurlyeq a d\left(f x_{n+1}, f x_{n}\right)+b d\left(f x_{n+1}, T x_{n+1}\right)+c d\left(f x_{n}, T x_{n}\right) \\
& =a d\left(f x_{n}, f x_{n+1}\right)+b d\left(f x_{n+1}, f x_{n}\right)+c d\left(f x_{n}, f x_{n-1}\right) .
\end{aligned}
$$

Thus, we have

$$
(1-c) d\left(f x_{n-1}, f x_{n}\right) \succcurlyeq(a+b) d\left(f x_{n+1}, f x_{n}\right) .
$$

Hence

$$
d\left(f x_{n+1}, f x_{n}\right) \preccurlyeq \frac{1-c}{a+b} d\left(f x_{n-1}, f x_{n}\right) .
$$

In Case (1), we let

$$
\lambda=\frac{1-b}{a+c}
$$

and in Case (2), we let

$$
\lambda=\frac{1-c}{a+b} .
$$

Thus in both cases, we have $\lambda<1$ and

$$
d\left(f x_{n+1}, f x_{n}\right) \preccurlyeq \lambda d\left(f x_{n-1}, f x_{n}\right) .
$$


By (4), we have

$$
\begin{aligned}
d\left(f x_{n+1}, f x_{n}\right) & \preccurlyeq \lambda d\left(f x_{n-1}, f x_{n}\right) \\
& \preccurlyeq \lambda^{2} d\left(f x_{n-2}, f x_{n-1}\right) \\
& \vdots \\
& \preccurlyeq \lambda^{n} d\left(f x_{0}, f x_{1}\right) .
\end{aligned}
$$

So for $m>n$, we have

$$
\begin{aligned}
d\left(f x_{n}, f x_{m}\right) & \preccurlyeq d\left(f x_{n}, f x_{n+1}\right)+d\left(f x_{n+1}, f x_{n+2}\right)+\cdots+d\left(f x_{m-1}, f x_{m}\right) \\
& \preccurlyeq\left(\lambda^{n}+\lambda^{n+1}+\cdots+\lambda^{m-1}\right) d\left(f x_{0}, f x_{1}\right) \\
& \preccurlyeq \lambda^{n} \sum_{i=0}^{+} \infty \lambda^{i} d\left(f x_{0}, f x_{1}\right) \\
& =\frac{\lambda^{n}}{1-\lambda} d\left(f x_{0}, f x_{1}\right) .
\end{aligned}
$$

Let $\theta \ll c$ be given, choose $\delta>0$ such that $c+N_{\delta}(0) \subseteq P$, where

$$
N_{\delta}(0)=\{y \in E:\|y\|<\delta\} .
$$

Also, choose a natural number $N_{1}$ such that

$$
\frac{\lambda^{n}}{1-\lambda} d\left(f x_{0}, f x_{1}\right) \in N_{\delta}(0)
$$

for $m \geq N_{1}$. Then

$$
\frac{\lambda^{n}}{1-\lambda} d\left(f x_{0}, f x_{1}\right) \ll c
$$

for all $m \geq N_{1}$. Thus,

$$
d\left(f x_{n}, f x_{m}\right) \preccurlyeq \frac{\lambda^{n}}{1-\lambda} d\left(f x_{0}, f x_{1}\right) \ll c,
$$

for all $m>n$. Therefore $\left(T x_{n}\right)$ is a cauchy sequence in $(T X, d)$. Since $(T X, d)$ is a complete cone metric space, there is $u \in X$ such that $\left(T x_{n}\right)$ converges to $T u$ as $n \rightarrow$ $+\infty$. Hence $f x_{n}$ converges to Tu as $n \rightarrow+\infty$. Since $a+b+c>1$, we have $a, b$ and $c$ are not all 0 . So we have the following cases.

Case 1: If $a \neq 0$, then

$$
d\left(T x_{n}, T u\right) \succcurlyeq a d\left(f x_{n}, f u\right)+b d\left(f x_{n}, T x_{n}\right)+c d(f u, T u) \succcurlyeq a d\left(f x_{n}, f u\right) .
$$

Hence

$$
d\left(f x_{n}, f u\right) \preccurlyeq \frac{1}{a} d\left(T x_{n}, T u\right) .
$$

Let $\theta \ll c$ be given, choose $\delta>0$ such that $c+N_{\delta}(0) \subseteq P$, where

$$
N_{\delta}(0)=\{y \in E:\|y\|<\delta\} .
$$


Since $\frac{1}{a} d\left(T x_{n}, T u\right) \rightarrow \theta$. We choose a natural number $n_{0} \in \mathbf{N}$ such that

$$
\frac{1}{a} d\left(T x_{n}, T u\right) \in N_{\delta}(0),
$$

for $n \geq n_{0}$. Then

$$
\frac{1}{a} d\left(T x_{n}, T u\right) \ll c,
$$

for all $n \geq n_{0}$. Thus,

$$
d\left(f x_{n}, f u\right) \preccurlyeq \frac{1}{a} d\left(T x_{n}, T u\right) \ll c,
$$

for all $n \geq n_{0}$. Thus $f x_{n} \rightarrow f u$ as $n \rightarrow+\infty$. By uniqueness of limit, we have $T u=f u$. Therefore $T$ and $f$ have a coincidence point.

Case 2: If $b \neq 0$, then

$$
d\left(T u, T x_{n}\right) \succcurlyeq a d\left(f x_{n}, f u\right)+b d(f u, T u)+c d\left(f x_{n}, T x_{n}\right) \succcurlyeq b d(f u, T u) .
$$

Hence

$$
d(f u, T u) \preccurlyeq \frac{1}{b} d\left(T x_{n}, T u\right) .
$$

As similar proof of Case (1), we can show that $f u=T u$. Thus $f$ and $T$ have a coincidence point.

Case 3: If $c \neq 0$, then

$$
d\left(T x_{n}, T u\right) \succcurlyeq a d\left(f x_{n}, f u\right)+b d\left(f x_{n}, T x_{n}\right)+c d(T u, f u) \succcurlyeq c d(f u, T u) .
$$

Hence

$$
d(f u, T u) \preccurlyeq \frac{1}{c} d\left(T x_{n}, T u\right) .
$$

As similar proof of Case (1), we can show that $f u=T u$. Thus $f$ and $T$ have a coincidence point.

Corollary 2.1. Let $(X, d)$ be a cone metric space with a solid cone P. Let $T, f: X \rightarrow X$ be mappings satisfying:

$$
d(T x, T y) \succcurlyeq a d(f x, f y)+b d(f x, T x)
$$

for all $x, y \in X$ where $a, b \geq 0$ with $a+b>1$ and $b<1$. Suppose the following hypotheses:

(1) $f X \subseteq T X$.

(2) TX is a complete subspace of $X$.

Then $T$ and $f$ have a coincidence point.

Corollary 2.2. Let $(X, d)$ be a complete cone metric space with a solid cone P. Let T, $f$ $: X \rightarrow X$ be mappings satisfying:

$$
d(T x, T y) \succcurlyeq a d(f x, f y)
$$


for all $x, y \in X$ where $a>1$. Suppose the following hypotheses:

(1) $f X \subseteq T X$.

(2) TX is a complete subspace of $X$.

Then $T$ and $f$ have a coincidence point.

Corollary 2.3. Let $(X, d)$ be a complete cone metric space with a solid cone P. Let $T$ : $X \rightarrow X$ be a surjective mapping satisfying:

$$
d(T x, T y) \succcurlyeq a d(x, y)+b d(x, T x)+c d(y, T y)
$$

for all $x, y \in X$ where $a, b, c \geq 0$ with $a+b+c>1$. Suppose $b<1$ or $c<1$. Then $T$ has a fixed point.

Proof. Follows from Theorem 2.1 by taking $f=I$, the identity map.

Corollary 2.4. Let $(X, d)$ be a complete cone metric space with a solid cone P. Let $T$ : $X \rightarrow X$ be a surjective mapping satisfying:

$$
d(T x, T y) \succcurlyeq a d(x, y)
$$

for all $x, y \in X$ where with $a>1$. Then $T$ has a fixed point.

Putting $E=\mathbf{R}, P=\{x \in \mathbf{R}: x \geq 0\}$ and $d: X \times X \rightarrow \mathbf{R}$ in Corollaries 2.1 and 2.2, we have the following results:

Corollary 2.5. Let $(X, d)$ be a complete metric space. Let $T: X \rightarrow X$ be a surjective mapping satisfying:

$$
d(T x, T y) \geq a d(x, y)+b d(x, T x)
$$

for all $x, y \in X$ where $a, b \geq 0$ with $a+b>1$ and $b<1$. Then $T$ has a fixed point.

Corollary 2.6. Let $(X, d)$ be a complete metric space. Let $T: X \rightarrow X$ be a surjective mapping satisfying:

$$
d(T x, T y) \geq a d(x, y)+b d(y, T y)
$$

for all $x, y \in X$ where $a, b \geq 0$ with $a+b>1$ and $b<1$. Then $T$ has a fixed point.

Now, we present a fixed point theorem for two maps.

Theorem 2.2. Let $T, S: X \rightarrow X$ be two surjective mappings of a complete cone metric space $(X, d)$ with a solid cone $P$. Suppose that $T$ and $S$ satisfying the following inequalities

$$
d(T(S x), S x)+k d(T(S x), x) \succcurlyeq a d(S x, x)
$$

and

$$
d(S(T x), T x)+k d(S(T x), x) \succcurlyeq b d(T x, x)
$$

for all $x \in X$ and some nonnegative real numbers $a, b$ and $k$ with $a>1+2 k$ and $b$ $>1+2 k$. If $T$ or $S$ is continuous, then $T$ and $S$ have a common fixed point

Proof. Let $x_{0}$ be an arbitrary point in $X$. Since $T$ is surjective, there exists $x_{1} \in X$ such that $x_{0}=T x_{1}$. Also, since $S$ is surjective, there exists $x_{2} \in X$ such that $x_{2}=S x_{1}$. Continuing this process, we construct a sequence $\left(x_{n}\right)$ in $X$ such that $x_{2 n}=T x_{2 n+1}$ and $x_{2 n+1}=S x_{2 n+2}$ for all $n \in \mathbf{N} \cup\{0\}$. Now, for $n \in \mathbf{N} \cup\{0\}$, we have

$$
d\left(T\left(S x_{2 n+2}\right), S x_{2 n+2}\right)+k d\left(T\left(S x_{2 n+2}\right), x_{2 n+2}\right) \succcurlyeq a d\left(S x_{2 n+2}, x_{2 n+2}\right) .
$$


Thus, we have

$$
d\left(x_{2 n}, x_{2 n+1}\right)+k d\left(x_{2 n}, x_{2 n+2}\right) \succcurlyeq a d\left(x_{2 n+1}, x_{2 n+2}\right),
$$

which implies that

$$
d\left(x_{2 n}, x_{2 n+1}\right)+k d\left(x_{2 n}, x_{2 n+1}\right)+k d\left(x_{2 n+1}, x_{2 n+2}\right) \succcurlyeq a d\left(x_{2 n+1}, x_{2 n+2}\right) .
$$

Hence

$$
d\left(x_{2 n+1}, x_{2 n+2}\right) \preccurlyeq \frac{1+k}{a-k} d\left(x_{2 n}, x_{2 n+1}\right)
$$

On other hand, we have

$$
d\left(S\left(T x_{2 n+1}\right), T x_{2 n+1}\right)+k d\left(S\left(T x_{2 n+1}\right), x_{2 n+1}\right) \succcurlyeq b d\left(T x_{2 n+1}, x_{2 n+1}\right) .
$$

Thus, we have

$$
d\left(x_{2 n-1}, x_{2 n}\right)+k d\left(x_{2 n-1}, x_{2 n+1}\right) \succcurlyeq b d\left(x_{2 n}, x_{2 n+1}\right) .
$$

Since $d\left(x_{2 n-1}, x_{2 n}\right)+d\left(x_{2 n}, x_{2 n+1}\right) \geqslant d\left(x_{2 n-1}, x_{2 n+1}\right)$, we have

$$
d\left(x_{2 n-1}, x_{2 n}\right)+k d\left(x_{2 n-1}, x_{2 n}\right)+k d\left(x_{2 n}, x_{2 n+1}\right) \succcurlyeq b d\left(x_{2 n}, x_{2 n+1}\right) .
$$

Hence

$$
d\left(x_{2 n}, x_{2 n+1}\right) \preccurlyeq \frac{1+k}{b-k} d\left(x_{2 n-1}, x_{2 n}\right)
$$

Let

$$
\lambda=\max \left\{\frac{1+k}{a-k}, \frac{1+k}{b-k}\right\} .
$$

Then by combining (7) and (8), we have

$$
d\left(x_{n}, x_{n+1}\right) \leq \lambda d\left(x_{n-1}, x_{n}\right) \quad \forall n \in \mathbf{N} \cup\{0\} .
$$

Repeating (9) $n$-times, we get

$$
d\left(x_{n}, x_{n+1}\right) \preccurlyeq \lambda^{n} d\left(x_{0}, x_{1}\right) .
$$

Thus, for $m>n$, we have

$$
\begin{aligned}
d\left(x_{n}, x_{m}\right) & \preccurlyeq d\left(x_{n}, x_{n+1}\right) \cdots+d\left(x_{m-1}, x_{m}\right) \\
& \preccurlyeq\left(\lambda^{n}+\cdots+\lambda^{m-1}\right) d\left(x_{0}, x_{1}\right) \\
& \preccurlyeq \frac{\lambda^{n}}{1-\lambda} d\left(x_{0}, x_{1}\right) .
\end{aligned}
$$

As similar arguments to proof of Theorem 2.1, we can show that $\left(x_{n}\right)$ is a Cauchy sequence in the complete cone metric space $(X, d)$. Then there exists $v \in X$ such that $x_{n} \rightarrow v$ as $n \rightarrow+\infty$. Therefore $x_{2 n+1} \rightarrow v$ and $x_{2 n+2} \rightarrow v$ as $n \rightarrow+\infty$. Without loss of generality, we may assume that $T$ is continuous, then $T x_{2 n+1} \rightarrow T v$ as $n \rightarrow+\infty$. But $T x_{2 n+1}=x_{2 n} \rightarrow v$ as $n \rightarrow+\infty$. Thus, we have $T v=v$. Since $S$ is surjective, there exists $w \in X$ such that $S w=v$. Now,

$$
d(T(S w), S w)+k d(T(S w), w) \succcurlyeq a d(S w, w),
$$


implies that $k d(v, w) \geqslant a d(v, w)$. Thus

$$
d(v, w) \preccurlyeq \frac{k}{a} d(v, w) .
$$

Since $a>k$, we conclude that $d(v, w)=\theta$. So $v=w$. Hence $T v=S v=v$. Therefore $v$ is a common fixed point of $T$ and $S$.

By taking $\mathrm{b}=a$ in Theorem 2.2, we have the following result.

Corollary 2.7. Let $T, S: X \rightarrow X$ be two surjective mappings of a complete cone metric space $(X, d)$ with a solid cone $P$. Suppose that $T$ and $S$ satisfying the following inequalities

$$
d(T(S x), S x)+k d(T(S x), x) \succcurlyeq a d(S x, x)
$$

and

$$
d(S(T x), T x)+k d(S(T x), x) \succcurlyeq a d(T x, x)
$$

for all $x \in X$ and some nonnegative real numbers $a$ and $k$ with $a>1+2 k$. If $T$ or $S$ is continuous, then $T$ and $f$ have a common fixed point

By taking $S=T$ in Corollary 2.7, we have the following corollary.

Corollary 2.8. Let $T: X \rightarrow X$ be a surjective mapping of a complete cone metric space $(X, d)$ with a solid cone $P$. Suppose that $T$ satisfying

$$
d(T(T x), T x)+k d(T(T x), x) \succcurlyeq a d(T x, x)
$$

for all $x \in X$ and some nonnegative real number $a$ and $k$ with $a>1+2 k$. If $T$ is continuous, then $T$ has a fixed point.

Now, we present some examples to illustrate the useability of our results.

Example 2.1. (The case of normal cone) Let $X=[0,+\infty), E=\mathbf{R}^{2}$. Let $P=\{(a, b): a \geq$ $0, b \geq 0\}$ be the cone with $d(x, y)=(|x-y|,|x-y|)$. Then $(X, d)$ is a complete cone metric space. Define $T: X \rightarrow X$ by $T x=2 x$. Then $T$ has a fixed point.

Proof. Note that

$$
d(T(T x), T x)+d(T(T x), x) \geq 4 d(T x, x)
$$

for all $x \in X$. Thus $T$ satisfies all the hypotheses of Corollary 2.8 and hence $T$ has a fixed point. Here 0 is the fixed point of $T$.

Example 2.2. (The case of non-normal cone) Let $X=[0,1], E=C_{\mathbf{R}}^{1}([0,1])$. Let $P=$ $\{\varphi \in E: \varphi(t) \geq 0, t \in[0,1]\}$. Define the mapping $d: X \times X \rightarrow E$ by

$$
d(x, y)(t):=|x-y| \phi(t),
$$

where $\varphi \in P$ is a fixed function, for example $\varphi(t)=e^{t}$. Define $T, f: X \rightarrow X$ by $f x=\frac{1}{16} x$ and $f x=\frac{1}{16} x$. Then $T$ and $f$ have a coincidence point.

Proof. Note that

$$
\begin{aligned}
d(T x, T y)(t) & =\left|\frac{1}{4} x-\frac{1}{4} y\right| e^{t} \\
& =4\left|\frac{1}{16} x-\frac{1}{16} y\right| e^{t} \\
& =4 d(f x, f y)(t)
\end{aligned}
$$


for all $x, y \in X$ and $t \in[0,1]$. Thus $T$ and $f$ satisfy all the hypotheses of Corollary 2.2 and hence $T$ and $f$ have a coincidence point. Here 0 is the coincidence point of $T$ and f.

\section{Remarks:}

(1) Theorem 4.1 of [29] is a special case of Theorem 2.2.

(2) Corollary 4.1 of [29] is a special case of Corollary 2.8.

(3) Theorem 4 of [31] is a special case of Corollary 2.8.

\section{Acknowledgements}

The authors thank the editor and the referees for their useful comments and suggestions.

\section{Authors' contributions}

All authors contributed equally and significantly in writing this article. All authors read and approved the final manuscript.

\section{Competing interests}

The authors declare that they have no competing interests.

Received: 11 October 2011 Accepted: 20 February 2012 Published: 20 February 2012

\section{References}

1. Huang, LG, Zhang, X: Cone metric spaces and fixed point theorems of contractive mappings. J Math Anal Appl. 332, 1468-1476 (2007). doi:10.1016/j.jmaa.2005.03.087

2. Arshad, M, Azam, A, Beg, l: Common fixed points of two maps in cone metric spaces. Rend Circ Mat Palermo. 57, 433-441 (2008). doi:10.1007/s12215-008-0032-5

3. Arshad, M, Azam, A, Vetro, P: Some common fixed point results in cone metric spaces. Fixed Point Theory Appl 2009, 11 (2009). (Article ID 493965)

4. Abbas, M, Ali Khan, M, Radenović, S: Common coupled fixed point theorems in cone metric spaces for $w$-compatible mappings. Appl Math Comput. (2010)

5. Abbas, M, Rhoades, BE: Fixed and periodic point results in cone metric spaces. Appl Math Lett. 22, 511-515 (2009). doi:10.1016/j.aml.2008.07.001

6. Abbas, M, Jungck, G: Common fixed point results for noncommuting mappings without continuity in cone metric spaces. J Math Anal Appl. 341, 416-420 (2008). doi:10.1016/j.jmaa.2007.09.070

7. Altun, I, Durmaz, G: Some fixed point theorems on ordered cone metric spaces. Rend Circ Mat Palermo. 58, 319-325 (2009). doi:10.1007/s12215-009-0026-y

8. Altun, I, Damjanović, B, Djorić, D: Fixed point and common fixed point theorems on ordered cone metric spaces. Appl Math Lett. 23, 310-316 (2010). doi:10.1016/j.aml.2009.09.016

9. Aydi, H, Nashine, HK, Samet, B, Yazidi, H: Coincidence and common fixed point results in partially ordered cone metric spaces and applications to integral equations. Nonlinear Anal. 74, 6814-6825 (2011). doi:10.1016/..na.2011.07.006

10. Aydi, H, Samet, B, Vetro, C: Coupled fixed point results in cone metric spaces for compatible mappings. Fixed Point Theory Appl. 2011, 27 (2011). doi:10.1186/1687-1812-2011-27

11. Azam, A, Beg, I, Arshad, M: Fixed point in topological vector space-valued cone metric spaces. Fixed Point Theory Appl 2010, 9 (2010). (Article ID 604084)

12. Choudhury, BS, Metiya, N: Fixed points of weak contractions in cone metric spaces. Nonlinear Anal. 72, 1589-1593 (2010). doi:10.1016/j.na.2009.08.040

13. Choudhury, BS, Metiya, N: The point of coincidence and common fixed point for a pair of mappings in cone metric spaces. Comput Math Appl. 60, 1686-1695 (2010). doi:10.1016/j.camwa.2010.06.048

14. Dordivić, M, Dorić, D, Kadelburg, Z, Radenović, S, Spasić, D: Fixed point results under c-distance in tvs-cone metric spaces. Fixed Point Theory Appl. 2011, 29 (2011). doi:10.1186/1687-1812-2011-29

15. Di Bari, C, Vetro, P: Weakly $\varphi$-pairs and common fixed points in cone metric spaces. Rend Circ Mat Palermo. 58 125-132 (2009). doi:10.1007/s12215-009-0012-4

16. Di Bari, D, Vetro, P: $\varphi$-pairs and common fixed points in cone metric spaces. Rend Circolo Matematico di Palermo. 57 , 279-285 (2008). doi:10.1007/s12215-008-0020-9

17. Wei-Shih, Du: A note on cone metric fixed point theory and its equivalence. Nonlinear Anal. 72, 2259-2261 (2010). doi:10.1016/j.na.2009.10.026

18. Ilić, D, Rakočević, V: Quasi-contraction on a cone metric space. Appl Math Lett. 22, 728-731 (2009). doi:10.1016/j. aml.2008.08.011

19. llić, D, Rako[001]ević, V: Common fixed points for maps on cone metric space. J Math Anl Appl. 341, 876-882 (2008). doi:10.1016/j.jmaa.2007.10.065

20. Janković, S, Kadelburg, Z, Radenović, S, Rhoades, BE: Assad-Kirk-Type fixed point theorems for a pair of nonself mappings on cone metric spaces. Fixed Point Theory Appl 2009 (2009). (Article ID 761086)

21. Janković, S, Golubović, Z, Radenović, S: Compatible and weakly compatible mappings in cone metric spaces. Math Comput Model. 52, 1728-1738 (2010). doi:10.1016/j.mcm.2010.06.043

22. Kadelburg, Z, Pavlović, M, Radenović, S: Common fixed point theorems for ordered contractions and quasicontractions in ordered cone metric spaces. Comput Math Appl. 59, 3148-3159 (2010). doi:10.1016/j.camwa.2010.02.039 
23. Khojasteh, F, Razani, A, Moradi, S: A fixed point of generalized $T_{F}$-contraction mappings in cone metric spaces. Fixed Point Theory Appl. 2011, 14 (2011). doi:10.1186/1687-1812-2011-14

24. Sumitra, R, Rhymend Uthariaraj, R, Hemavathy, R, Vijayaraju, P: Common fixed point theorem for non-self mappings satisfying generalized Ćirić type contraction condition in cone metric space. Fixed Point Theory Appl 2010, 17 (2010). (Article ID 408086)

25. Shatanawi, W: Some common coupled fixed point results in cone metric spaces. Int J Math Anal. 4, 2381-2388 (2010)

26. Shatanawi, W: Partially ordered cone metric spaces and coupled fixed point results. Comput Math Appl. 60, 2508-2515 (2010). doi:10.1016/j.camwa.2010.08.074

27. D Turkoglu, D, Abuloha, M: Cone metric spaces and fixed point theorems in diametrically contractive mappings. Acta Mathematica Sinica (English Series). 26, 489-496 (2010)

28. Vetro, P: Common fixed points in cone metric spaces. Rend Circ Mat Palermo. 56, 464-468 (2010)

29. Şahin, İ, Telci, M: Fixed points of contractive mappings on complete cone metric spaces. Hacet J Math Stat. 38, 59-67 (2009)

30. 区ahin, İ, Telci, M: A theorem on common fixed points of expansion type mappings in cone metric spaces. An St Univ Ovidius Constanța. 18, 329-336 (2010)

31. Wang, SZ, Li, BY, Gao, ZM, Iseki, K: Some fixed point theorems on expansion mappings. Math Japon. 29, 631-636 (1984)

doi:10.1186/1687-1812-2012-19

Cite this article as: Shatanawi and Awawdeh: Some fixed and coincidence point theorems for expansive maps in cone metric spaces. Fixed Point Theory and Applications 2012 2012:19.

\section{Submit your manuscript to a SpringerOpen ${ }^{\odot}$} journal and benefit from:

- Convenient online submission

- Rigorous peer review

- Immediate publication on acceptance

- Open access: articles freely available online

- High visibility within the field

- Retaining the copyright to your article

Submit your next manuscript at $\gg$ springeropen.com 